City University of New York (CUNY) CUNY Academic Works

2020

\title{
Mathematics identity and achievement among Black students
}

Lidia Gonzalez

York College, City University of New York

Shawnda Chapman Brown

Juan Battle

CUNY Graduate Center

\section{How does access to this work benefit you? Let us know!}

More information about this work at: https://academicworks.cuny.edu/yc_pubs/286

Discover additional works at: https://academicworks.cuny.edu

This work is made publicly available by the City University of New York (CUNY).

Contact: AcademicWorks@cuny.edu 


\title{
Mathematics identity and achievement among Black students
}

\author{
Lidia Gonzalez $^{1}$ | Shawnda Chapman ${ }^{2}$ | Juan Battle ${ }^{3}$
}

\author{
${ }^{1}$ Department of Mathematics and Computer \\ Science, York College, City University of \\ New York, Jamaica, NY, USA \\ ${ }^{2}$ Independent Research Consultant \\ ${ }^{3}$ Department of Sociology, Urban \\ Education, Public Health, \& Social Welfare, \\ CUNY Graduate Center, New York, NY, \\ USA \\ Correspondence \\ Lidia Gonzalez, Department of \\ Mathematics and Computer Science, York \\ College, City University of New York, \\ Jamaica, NY, USA. \\ Email: lgonzalez@york.cuny.edu
}

\begin{abstract}
Employing data from the National Center of Educational Statistics' High School Longitudinal Study and utilizing critical race theory and intersectionality as theoretical frameworks, this article interrogates the relationship between mathematics identity and math success for a nationwide sample of Black secondary school students. More specifically, hierarchical regression modeling is employed to examine the relative impact of math identity, demographic variables, and school/parent social capital variables on the math grade point averages of this sample. The article ends with a discussion of specific steps for teaching mathematics that put the identity of those from traditionally marginalized communities at the center of mathematics instruction. Thus making experiences, histories, culture, and abilities essential elements of students' learning, that are to be supported and built upon.
\end{abstract}

\section{K E Y W O R D S}

Black students, mathematics education, mathematics identity, mathematics achievement

\section{1 | INTRODUCTION}

A student's ability to succeed academically in mathematics has far-reaching consequences. Mathematical proficiency has been described as a gate-keeper to future success in life including college completion, academic attainment, employment status, salary, and socioeconomic standing (Douglas \& Attewell, 2017; Moses \& Cobb, 2001; Stinson, 2004). As such it is quite troubling that for many students, academic success in mathematics is often elusive. Such is the case for large numbers of students from traditionally under-represented groups in mathematics such as women, Blacks, and Latinx students who, because of historical, social, and economic realities, have struggled to gain full participation in academic mathematics and our society (Gutiérrez, 2013a, 2013b; Moses \& Cobb, 2001).

One reason students struggle with mathematics is that it is often taught in ways that are disconnected from students' experiences, making it hard for students to relate to the material (Gutstein, 2012; Martin, 2009). Additionally, the work of Stigler and Hiebert (1999) sheds light on the cultural scripts employed by mathematics teachers, which tend to prioritize procedural over conceptual understanding. A student, therefore, may be unaware of why a procedure works, in what cases it may not work, or how to deal with problems that deviate slightly from those presented. This makes it difficult for students to retain what they have learned and to have a solid foundation upon which to build their mathematical knowledge. Furthermore, opportunities to collaborate with peers on challenging tasks in an environment that is culturally responsive is seen as enhancing students' learning of mathematics (Martin, 2012; Matthews et al., 2013; Stein et al., 2000). Culturally responsive teaching draws upon the prior experiences, performance styles, and cultural background of students to teach diverse students in ways that are appropriate and effective for them (Gay, 2000). In doing so, students' identities are not only acknowledged but built upon and valued. Though such environments have showed to support students' learning, these environments remain unavailable to most students, especially students of color (Ladson-Billings, 2006).

Lastly, success in mathematics is affected by a student's perceived mathematical ability. A Student who fails to see themselves as mathematically capable or who deem themselves not a math person may struggle to develop an 
academic identity that fosters the educational success. That it is socially acceptable to admit that one is bad at math further complicates the role that mathematics identity has on success in the discipline. It means, on the one hand, that individuals, especially those who teach young children, may pass their fear of the subject onto their students. On the other hand, the commonly held belief that most people are unable to succeed allows wide-spread failure in the subject to be taken as a given. It further places blame on individuals themselves, thus shifting the conversation away from social forces that impact the academic success in mathematics (Gonzalez, 2016). Among these are socioeconomic status, geography, and access to high quality mathematics instruction and upper-level courses.

This study examines the role of mathematics identity on the academic achievement of Black students in mathematics as measured by their high school mathematics grade point average. Furthermore, we consider how, if at all, this role shifts, when we control for key variables: socioeconomic status, parents' social capital, and the academic opportunities available to students at their schools. Current research addresses issues of mathematics identity and its role on academic attainment for various populations, Blacks among them. These works, however, are overwhelmingly qualitative in nature and draw from a relatively small number of cases. While such work has been valuable, a large-scale study that looks to connect these variables quantitatively for a national sample of students is needed to contextualize the work that presently exists and speak to the magnitude of the issue at hand. This study aims to do just that.

\section{I LITERATURE REVIEW}

A rich literature exploring the influences on students' ability to learn mathematics includes characteristics of students, teachers, curricula; the role of environmental factors and educational policies; and social, cultural, and historical realities. From among an ever-growing list of possible factors, we have deemed as both impactful and malleable the construct of identity. The malleable nature of identity is important because it provides an avenue for supporting success. We consider what influences identity and the unique ways that Black students' identity is complicated by race, class, and gender. Therefore, while the literature on racialized mathematics identity is salient, we include as well relevant research on demographic variables such as region, socioeconomic status, and gender. Lastly, we acknowledge the manifestation of these as both affordances and challenges in the pursuit of academic success. That is, we include literature that speaks to the impact of parents' social capital and the characteristics of schools as measured by the presence of opportunities to engage with higher-level content such as advanced placement (AP) courses.

\section{1 | Math identity}

Mathematics identity consists of "the dispositions and deeply held beliefs that individuals develop about their ability to participate and perform effectively in mathematical contexts and to use mathematics to change the conditions of their lives" and "a person's self-understanding and how others see [the person] in the context of doing mathematics" (Martin, 2009, pp. 136-137). It has been posited that mathematics identity affects one's perception of the discipline, one's academic identity and, ultimately, one's success in the subject. In line with the self-fulfilling prophecy, a term coined by Robert K. Merton in 1948, an individual who doubts the ability to succeed will most likely be unsuccessful, in part because they neglect to engage in behaviors that might result in success. A student may profess that studying and practice problems are germane to success in mathematics yet sabotage their own success because of beliefs about their propensity for failure are deeply ingrained. This may even occur without students being consciously aware of it.

Additionally, we must consider the impact of stereotype threat on mathematics identity and success, especially among women and other traditionally under-represented groups in mathematics (Berry, 2008; McGee, 2013a; Stinson, 2008). Stereotype threat is the fear that one will act in ways that reinforce negative stereotypes about one's group (Steele, 2006). There is a negative stereotype of Blacks as nonintellectual, which Black students may fear reinforcing. Furthermore, Martin $(2009,2013)$ speaks of racialized mathematics identity. Here, the concept of mathematics identity is inextricably linked to an individual's identity as a Black person. One cannot be separated from the other.

Similarly, the impact of stereotype threat on girls in mathematics has been studied extensively by Sadker and Sadker (2012), who note that the valued ways of acting in mathematics classrooms do not often align with the ways in which girls learn best. Specifically, collaborative group work and openended problems are less likely to be employed, and teachers favor students, most often boys, who work individually to obtain answers quickly. Despite this, programs can increase the participation and success in mathematics of Black students. Researchers found in one such program that Black males with opportunities to learn mathematics in "culturally receptive climates" develop positive mathematics identities, a precursor to academic success in the discipline (Berry et al., 2014). Supportive environments can challenge the isolation marginalized students feel when studying mathematics or working in mathematics-related careers, and they foster success among individuals from groups traditionally under-represented in mathematics (Solomon et al., 2011).

Interestingly, it has been shown that the ability to do mathematics, on its own, is not a sufficient condition to ensure a strong mathematics identity (Solomon, 2009). In addition 
to having some success in the subject, students need to be involved in the work of mathematicians to see themselves as mathematicians or mathematicians in training. Exploring open-ended problems and collaborating on original research may be just as important.

\section{2 | Socioeconomic status}

Much has been written about the effects of socioeconomic class (SES) on academic attainment (Anyon, 2014; Gutstein, 2012; Martin, 2009). Low SES has been associated with lower academic achievement and attainment. We find that students from poorer families miss more days of school than their more affluent counterparts (Burton, 2003), while schools serving more affluent communities tend to have more academic and financial resources, which adds to the disparities that exist between groups (Anyon, 1997; Burton, 2003). Tied to this is the role that geography plays, in part, because neighborhoods and schools are segregated by SES.

Segregation is further reinforced through standardized testing and tracking. These practices filter out Black students whose social and cultural capital is not well aligned with standard measures of assessment and who have traditionally received fewer enrichment opportunities, unequal access to upper-level mathematics courses, and a poorer-quality education, in general (Berry et al., 2013). The net effect of this reality is the reproduction of the inherently unjust social system in which we live. Large social structures, such as the educational system, tend to reproduce themselves (Bourdieu \& Passeron, 1990). Anyon's (2014) work, while acknowledging this tendency, puts forward several social and educational reforms aimed at disrupting the cycle of social reproduction.

\subsection{Social capital}

Social capital are the resources that individuals can tap into to further their position in society. These include relationships with individuals or organizations, knowledge of a social nature, educational resources, and knowledge of valued social norms. A mis-alignment between the social capital of Black students and that which is valued in schooling may result in Blacks missing the full benefits of the educational system.

The mathematical ability of Black students has been historically positioned against the ability of White students (Martin, 2013). Specifically, Black males have been labeled as deficient in mathematics and are disproportionately represented in disciplinary actions (Booker \& Mitchell, 2011; Gregory et al., 2010). These students often live up to the low academic expectations placed on them as they are filtered into programs for "at risk" students and work their way from academic disciplinary action to the criminal justice system. This reality persists despite numerous reforms aimed at improving the mathematical success of Black students. However, well-meaning these reforms, Berry et al. (2013) note that the needs of Black children in mathematics have been ignored for decades. While individual programs may garner some success for the students involved in them, sweeping changes to the landscape of who is successful mathematically have not come to pass. Instead, we have incremental changes in the success of students from marginalized communities.

In an attempt to push back against the tendency to position and interpret the mathematical ability of Blacks against those of other groups, Flores (2007) encourages us to consider not an achievement gap, but rather an opportunity gap. In doing so, we focus not on the results of a system of unequal opportunity in which Blacks have less access to the educational opportunities and resources that encourage success, but on the inequitable system itself.

Martin (2013) notes that the tendency to replicate the unequal distribution of power and resources means that only incremental changes are likely to occur. He advocates for a resistance akin to that which drove the civil rights movement. Here, the emphasis is not on equality within the current inequitable framework, but a rethinking and reworking of the framework itself. Instead, Leonard and Martin (2013) propose that we consider mathematics learning and the development of identity through a framework of brilliance, leaving aside discourses framed by deficits and gaps between Blacks and those in the reference group (white men).

Black brilliance has been largely ignored by educators, educational researchers, and policy makers but is being taken up in more recent work. Additionally, such work increasingly includes voices of Black students (Berry, 2008; Jett, 2010; McGee, 2013b; Stinson, 2013). By doing so, the mathematical identities of Black students are increasingly characterized by the students themselves, adding positive characterizations of their identities as they relate to the teaching and learning of mathematics (Grant et al., 2015).

\section{3 | THEORETICAL FRAMEWORK}

This work is informed by critical race theory and intersectionality. Both reflect the interplay between various aspects of identity, culture, social life, and the power dynamics that exist within all social systems.

\section{1 | Critical (race) theory}

The overarching theory that drives this work is critical theory, broadly, and critical race theory, specifically. Critical theory draws from the Frankfurt school and is interested in 
unpacking issues of power and privilege inherent in all social systems, the educational system included. "Critical theorists take apart normalized notions of democracy, freedom, opportunity structures, and social justice to denounce systems of power and domination" (Kincheloe et al., 2018).

Acknowledging that race cannot be decoupled from academic identity and must be considered in the educational experiences of students has led to critical race theory, a staple in the tool boxes of educational researchers whose work strives to unpack the effects of power and privilege in the educational system (Ledesma \& Calderón, 2015). Here, this theory guides an analysis that, while focused on the mathematical identities of Black students and their effect on mathematics achievement, understands that this relationship exists within a system rife with inequality. In understanding this relationship we must pay mind to the social forces that impact the educational and cultural experiences of the students we aim to understand and better serve.

\section{2 | Intersectionality}

Intersectionality also guides this work by highlighting the unique experiences that exist for students from marginalized communities at the intersection of race, gender, and class (Crenshaw, 1991). The concept of intersectionality as defined by Cole (2009) is used to "describe analytic approaches that simultaneously consider the meaning and consequences of multiple categories of identity, difference and disadvantage" (p. 70). A more robust treatment of this theory is undertaken by Collins and Bilge (2016). The current research, in studying the impact of mathematics identity considers multiple identities and aspects of identity development. Racism and sexism play a critical role in the experiences of students of color as sites of marginalization (Browne \& Battle, 2018). When considering the developing identities of Black students, we must, therefore, attend to race, sex, and gender as forces that together create intersecting identities that cannot be separated and that, perhaps unequally, shape the lives of Black students by mutually constructing and supporting one another (Collins, 1999).

\section{4 | DATA AND METHODS}

\section{1 | Research questions}

The study aimed to answer the following research questions:

1. What is the relationship, if any, between mathematics identity and mathematics success as measured by math GPA is grade 11 for a nationwide sample of Black secondary school students? How, if at all, does this change when considering black males and black females?
2. What is the impact, if any, of demographic variables and school/parent social capital variables on student success in math as measured by math GPA is grade 11 for a nationwide sample of Black secondary school students? How, if at all, does this change when considering black males and black females?

\section{2 | Data collection}

The data for this research are from the High School Longitudinal Study (High School Longitudinal Study of 2009, 2009). It is designed by the National Center for Educational Statistics a primary federal entity for collecting and analyzing data related to education in the United States. The baseline survey was administered to 23,000 nineth-grade students in 2009. The sample included 944 schools, the 23,000 students and their parents and counselors, administrators, and teachers from the schools. The survey sampled public, private, and Catholic schools with nineth-grade students randomly selected from within each school. Follow-ups began in 2012 when the majority of the students would be in 11th grade. In 2013 high school transcripts were collected. Finally, the last follow-up occurred in 2016, for most students 3 years into their post-secondary education phase, when many students were either in college, employed, or having never attended college.

Surveys were collected from students, their parents, math teachers, school administrators, and school counselors. For the students, several domains of data were collected: interests and goals in regards to school generally and to STEM specifically; identity formation; academic behavior (e.g., attendance and study habits); attitudes and beliefs (e.g., self-efficacy); social and cultural experiences; exposure to STEM through school or home activities; as well as negative school and STEM experiences.

For parents, domains included demographics; sources and quality of information regarding college planning and financing; educational expectations; discussions about courses, postsecondary options, careers; support and resources for academic pursuits at home; school involvement. For the teachers sampled, domains included demographics; professional preparation and experience; perceptions of parental involvement; perceptions of educational leadership; math and science richness of the school; work-related attitudes (e.g., efficacy).

Again, for each student sampled, a school administrator and counselor were also sampled. For administrators, questions were asked about outreach and transition programs for eight graders; course availability and selection processes; planning for transition to postsecondary. Conversely, or counselors, questions centered around caseload; duties; how students enter pathways for postsecondary education and/or 
the workforce; course placement and advising; supports for struggling and excelling students.

Additionally, and particularly germane to this article, the survey included an algebra assessment in the fall of 9th grade (2009) and again in the spring of most students' 11th grade year (2012). A more thorough discussion of this data set, its components, and its utility for more elaborately examining math outcomes have all been documented elsewhere (Duprey et al., 2018; LoGerfo et al., 2011).

\section{3 | Dependent variable}

Math GPA is a variable for students' GPA for math courses as of the end of 11 th grade. It is on a $0-4.0$ scale. However, 0.25 is the lowest reported score in this data set.

\section{4 | Independent variables}

Math Identity is a composite variable taking the mean of the responses to the following questions: "9th grader sees himself/ herself as a math person," "Others see 9th graders as a math person," "How often 9th grader thinks he/she really understands math assignments," "9th grader is enjoying fall 2009 math course very much," "9th grader confident can do excellent job on fall 2009 math tests," "9th grader can master skills in math course," and "9th grader can do excellent job on math assignments" All variables ranged 1-4, (strongly agree to strongly disagree). However, responses were reverse coded so that higher numbers represent more positive math identity values for ease of analysis. This composite variable has an alpha of .72. Because identity can be a precursor to action (Holland, 2001), students' identity can influence academic success. Martin (2009, 2012) and Gutiérrez (2013b, 2017) focus their work on the mathematics identity of students of color shedding light to the ways in which identity and achievement are linked. Martin (2000) focuses specifically on African American students noting that the students' identities as African Americans cannot be decoupled from their views of themselves as students of mathematics. Their work on the importance of the construct of mathematics identity on academic success makes its study essential if we are to better support these learners.

Socioeconomic Status is a standardized variable established as a continuous index score based on a combination of income, education, and occupational prestige. The scores are normalized. As such, positive scores refer to SES that is above the mean and negative ones below the mean. That socioeconomic status is linked to academic success is well-established (Burton, 2003; Martens et al., 2014).

Urbanicity is recoded into a series of dummy variables that reflects the schools urbanicity. Individually included are Suburban (1 for suburban and 0 for all else), Town (1 for town and 0 for all else), and Rural ( 1 for rural and 0 for all else), with Urban being the reference category.

Region is recoded into dummy variables. Individually included are northeast (northeast coded as 1 and other regions coded as 0 ), midwest (midwest coded as 1 and other regions coded as 0 ), and south (south coded as 1 and other regions coded as 0 ). West is the reference category.

Parent Social Capital is a count variable totaling the number of "yes" responses to the following questions: "Went to science or engineering museum with 9th grader in last year," "Worked or played on computer with 9th grader in last year," "Built or fixed something with 9th grader in last year," "Attended a school science fair with 9th grader in last year," "Helped 9th grader with a school science fair project in last year," and "Visited a library with 9th grader in last year." Particularly with respect to issues related to race and socioeconomic status, social capital affects the educational attainment (Prieur \& Savage, 2013; Tramonte \& Willms, 2010).

Parental Involvement is a count variable reflecting the number of "yes" responses to the following questions: "9th graders school was chosen," "attended a general school meeting since start of last school year," "Attended a PTO meeting since start of last school year," "Attended a parent-teacher conference since start of last school year," "Attended a school event since start of last school year," "Served as a school volunteer since start of last school year," "Met with a School Counselor since start of last school year," and "Parent helped teenager with homework." Researchers are clear that parental involvement promotes positive academic outcomes (Rothon et al., 2012).

Teacher Race is a variable indicative of the race of the student's teacher: Asian, Black, multi race, or White, with White being the reference category.

AP courses offered are a school-level variable noting the number of AP courses offered by the school in which the student is enrolled. Percent (\%) 12th graders taking AP courses are a school-level variable indicating the percentage of 12 thgrade students who have taken at least one AP course. We refer to all the AP courses offered by the school, not merely those in mathematics. The number of AP courses offered and the percentage of students taking such courses speak to the academic opportunities within a particular school. Unequal opportunities across schools that serve students with differing socioeconomic status have profound effects on the future of the students serviced by these (Anyon, 1997, 2014; Ladson-Billings, 2006).

\section{5 | RESULTS}

Table 1 shows a summary of the means, standard deviations, and other descriptive statistics for the dependent and independent variables. 
T A B L E 1 Means, standard deviations, ranges, and description of variables for Black students $(N=829)$

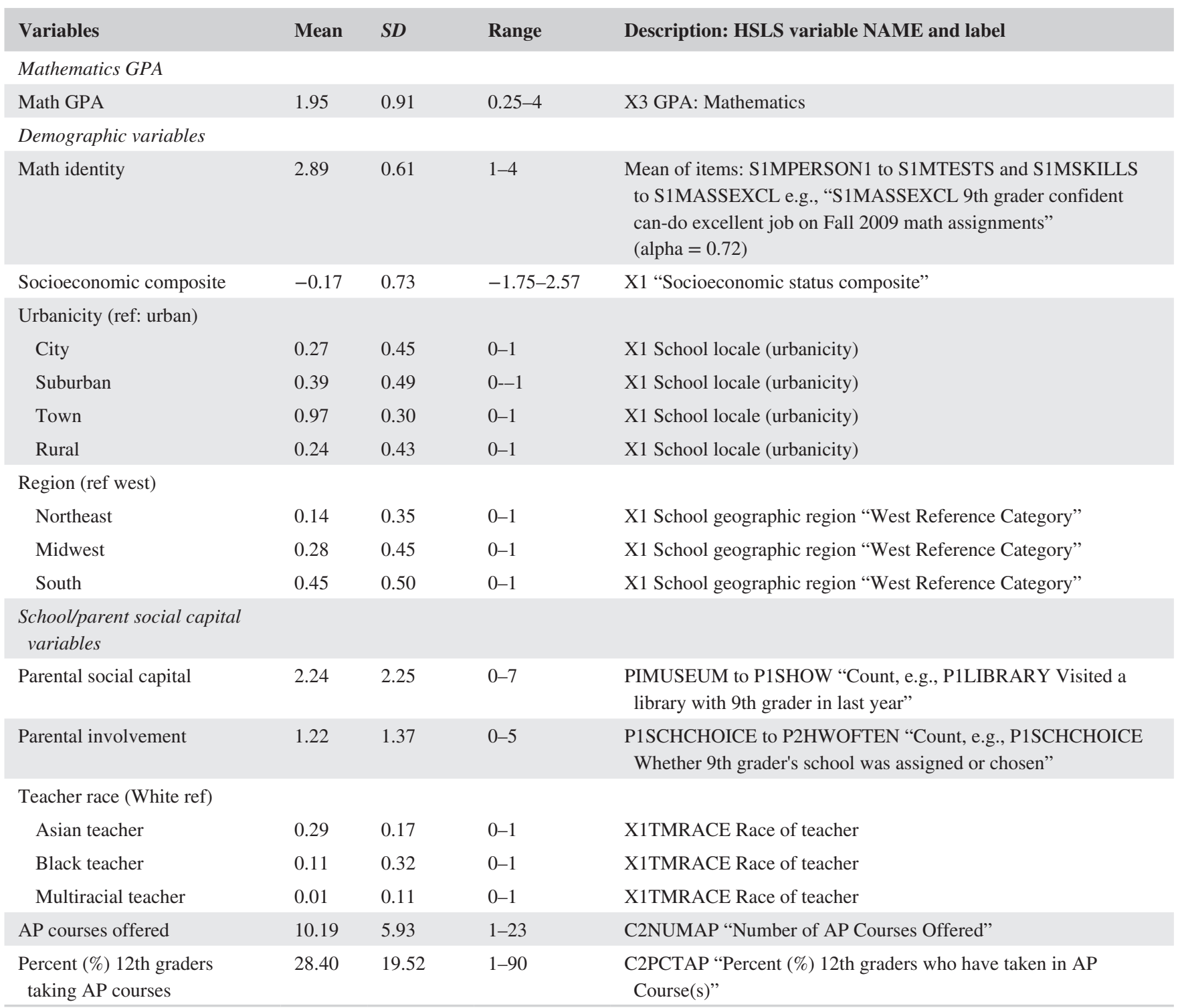

\subsection{Multivariate relationships}

To best understand the unique as well as additive contribution of math identity, key demographic variables, and school/ parent social capital on math GPA for Black students, and then, see how those relationships operate separately for Black female versus Black male students, we chose to use multiple regression. Furthermore, because we wanted to know how math identity operated alone/bivariately (see Model 1), as well as in the presence of the other domains (see Models 2 and 3), we performed hierarchical regression modeling. Ultimately nine models were run, three for all Black students, three for Black females, and three for Black males (Table 2).

Results indicate that math identity is positively robustly associated with math GPA. More specifically, this association held across all nine models was examined.
The second domain interrogated a series of demographic variables (see Models 2, 3, 5, 6, 8, and 9). The first variable in this domain-socioeconomic status-proved to be robustly and positively associated with math GPA. Higher levels of socioeconomic status produced higher levels of math GPA. Conversely, urbanicity-whether a student lived in an urban, suburban, town, or rural area-had no statistically significant impact. Similarly, region-whether a student lived in the west, northeast, Midwest, or south—had no statistically significant impact on math GPA.

The third domain added variables measuring school/parent social capital (see Models 3, 6, and 9). Here, parental social capital was entered first. It was not found to be statistically significant for the entire sample (see Model 3), females (see Model 6), nor or males (see Model 9). This same result also pertained to parental involvement. Specifically, it too was not found to be significant. 
TA B LE 2 OLS regression on math GPA for Black students (standard error in parenthesis)

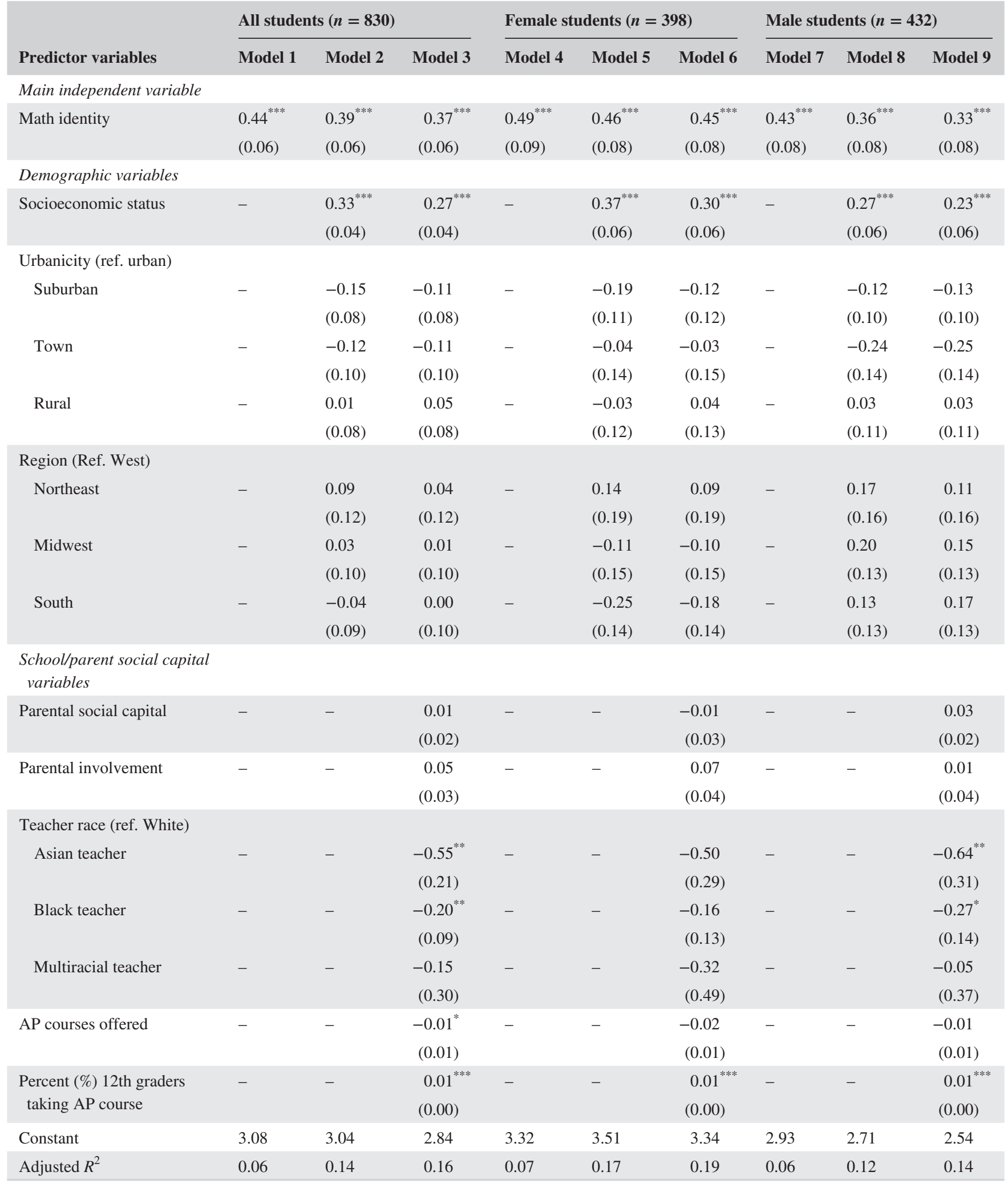

$* p<.05 ; * * p<.01 ; * * * p<.001$.

Conversely, there were some interesting findings for race of the teacher. For example, overall, Black students who had an Asian teacher performed more poorly than their counterparts who had a White teacher (see Model 3).
However, while that relationship holds for Black males (see Model 9), it does not hold for Black females (see Model 6). A very similar pattern exists when comparing having a Black teacher to having a White teacher. In short, while all 
Black students with Black teachers do less well than their counterparts with a White teacher, this relationship is true for Black males but not Black females. In sum, while the race of the teacher has no impact on math GPA for Black females, Black males do best with a White teacher, as compared to having an Asian or Black teacher. Conversely, having a multiracial teacher, as compared to a White teacher, has no impact on math GPA for neither Black female nor Black male students.

The impact of being in a school that offered AP courses had a minimal impact for all Black students; and that relationship actually disappears when examining the association within female and male students. Moreover, across all three models examined, the percent of 12th graders taking AP courses had a minimally positive, yet statistically significant, impact on math GPA. In short, the greater the percentage of 12th graders taking an AP course, the higher the math GPA.

\section{6 | DISCUSSION}

That mathematics identity is linked to success in the subject for the students in this study even while controlling for factors such as socioeconomic status and parents' social capital is a powerful and hopeful finding. It gives us a path to improving the educational experiences of Black students in mathematics. As students' views of themselves with respect to mathematics has a strong influence on their success in the subject, our efforts at meeting the needs of students should focus on strengthening their connection to the discipline. Rather than teach mathematics separate from the experiences of students, we must embrace the cultural, social, and historical experiences of our students and teach mathematics in a way that capitalizes on who students are. Culturally responsive teaching has been held up as a powerful way to build upon the experiences of students (Villegas \& Lucas, 2002). While such a pedagogical approach has been discussed for decades, mathematics still remains a discipline where we often neglect the cultural making it difficult for some to form strong a connection with the subject.

We can strengthen the mathematical identity of Black students by drawing upon the connections that exist between students and the discipline which Gutiérrez (2017) sees as part of humanizing mathematics education. We can, as an example, discuss the history of the subject highlighting the contributions Blacks have made. We can highlight and value the algorithms and techniques that grew out of the cultures and races represented by the students' in our classes. Ultimately, we can and should center mathematics instruction on the experiences of students. Gutstein and Peterson (2013) collect a number of projects and activities that do just that in their text Rethinking Mathematics: Teaching Social Justice by the Numbers. Students can learn about probability and statistics, as an example, through the study of racial profiling by examining the data on "random" traffic stops and comparing the percentage of students from various ethnicities that are stopped against the general population of a particular area. In doing so mathematics is transformed into a powerful tool to understand society and challenge the inequities therein. Teaching mathematics for social justice (MfSJ) is a natural pedagogy for doing this as it involves centering mathematics instruction on the experiences of students from marginalized communities while engaging them in the rigorous study of mathematics (Gonzalez, 2009, 2016; Gutstein, 2012). Regardless of the strategy employed, if we are to support the mathematical development of students from marginalized communities, we must create educational environments that support and value the racialized identities of these students. That mathematical identity is linked to success even when considering parental factors may seem counter-intuitive and yet it seems to be the case across all the models. One reason is the strength of the role of identity. Identity is a pre-curser to action and so seeing one's self as mathematically able leads to actions which strengthen the mathematical ability.

Another interesting finding is that the Black students in this study do better mathematically in schools where a higher percentage of students take AP classes but not in those where there is a higher number of AP courses. The distinction here is a valuable one. It is not enough that there be access to high quality upper-level mathematics courses (here measured by the number of AP courses offered). What matters is the percentage of students who make use of this access and actually enroll in the courses. As such a school with a high number of AP courses who serve a relatively small percentage of students is not really providing access to AP courses for their students as a whole. These opportunities exist for a small subset of the school's student population. This finding speaks to the need to go beyond access. It is not enough that these courses exist, rather we must find ways to encourage students from marginalized communities to take these courses and support them in doing so. Educational policies that challenge the unequal access that Black students have high quality upper-level courses taught by experienced teachers who hold high standards for students should be supported as part of a movement that completely overhauls the unequal distribution of academic resources and opportunities that continue in our geographically, racially, and economically segregated system of education.

One final result that bears reflection is that which indicates that while the race of the teacher has no impact on math GPA for Black females, Black males do best with a White teacher, as compared to having an Asian or Black teacher. This may lead some to mistakenly believe that white teachers are more effective when teaching Black males than those from other racial groups. However, we much keep in mind 
that the distribution of white teachers is not equal across schools. The percentage of non-white teachers is highest in underperforming schools, and as such, the results here may be speaking less to the quality of the teachers themselves and more to the type of school that the teachers work in.

\section{7 | IMPLICATIONS}

These findings have implications for teaching and learning mathematics at all levels. They speak to the need to teach mathematics in culturally, racially, and socially responsive ways. They highlight the connection between attending to a student's identity and supporting academic success in mathematics. They push us to think of mathematics not as context free but as context laden. They challenge us to embrace the brilliance that Black students bring to the mathematics classroom by building on their abilities, cultures, and experiences. Furthermore, while this article is focused on Black students, it can be argued that a focus on the connections between students' experiences and mathematics can affect all students who are presently marginalized in the discipline. That is, if we attend to the identities of our students, we can teach mathematics in powerful ways that humanize the discipline and bring students from underrepresented groups in mathematics into the circle of who can and will be successful. Socioeconomic status and parents' social capital are areas that are much harder to affect change in than identity. In essence this work finds that improving the mathematical abilities of marginalized students is within reach and what is required is for us to see, support, and build upon the brilliance these students bring to the classroom each day.

Among the limitations of this study is that students' success in mathematics was measured by math GPA in grade 11. There may be better indicators of students' mathematical ability such as overall math GPA or math GPA in a different grade. Additionally, while the analysis controlled for SES and social capital, there may be other variables that impact students' success in mathematics that we have omitted such as family composition, school district, or type of school attended. Despite these, the study does highlight the importance of mathematical identity on the academic success of Black students, regardless of variables such as socioeconomic status and social capital.

Given the results it may be fruitful for future research to focus on mathematics identity. Specifically, it may be useful for researchers to identify the ways in which positive mathematics identity can be fostered among Black students. Future work can go beyond how we might build upon students' experiences in the mathematics classroom and explore broadly the ways in which a strong positive mathematics identity comes to be. We might be able to determine what specific events, activities, or experiences lead to strong mathematics identity development among Black students. Once we understand the relevant experiences, we can then turn our attention to the development of curricula, activities, and educational policies that align with such experiences and in doing so better prepare Black students for success in mathematics both in the classroom and later on in life.

\section{REFERENCES}

Anyon, J. (1997). Ghetto schooling: A political economy of urban education. Teachers College Press.

Anyon, J. (2014). Radical possibilities: Public policy, urban education, and a new social movement (2nd ed.). Routledge.

Berry, R. Q., III. (2008). Access to upper-level mathematics: The stories of successful African American middle school boys. Journal for Research in Mathematics Education, 39(5), 464-488.

Berry, R. Q., III, Ellis, M., \& Hughes, S. (2014). Examining a history of failed reforms and recent stories of success: Mathematics education and Black learners of mathematics in the United States. Race, Ethnicity \& Education, 17(4), 540-568. https://doi. org/10.1080/13613324.2013.818534

Berry, R. Q., III, Pinter, H., \& McClain, O. (2013). A critical review of American K-12 mathematics education, 1954-present: Implications for the experiences and achievement of Black children. In J. Leonard \& D. B. Martin (Eds.), Beyond the numbers and toward new discourse: The brilliance of Black children in mathematics (pp. 23-53). Information Age.

Booker, K., \& Mitchell, A. (2011). Patterns in recidivism and discretionary placement in disciplinary alternative education: The impact of gender, ethnicity, age, and special education status. Education and Treatment of Children, 34(2), 193-208. https://doi.org/10.1353/ etc. 2011.0016

Bourdieu, P., \& Passeron, J. C. (1990). Reproduction in education, society and culture (Vol. 4). Sage.

Browne, A. P., \& Battle, J. (2018). Black family structure and educational outcomes: The role of household structure and intersectionality. Journal of African American Studies, 22(1), 77-93.

Burton, L. (Ed.). (2003). Which way social justice in mathematics education? Praeger.

Cole, E. R. (2009). Intersectionality and research in psychology. American Psychologist, 64(3), 170-180. https://doi.org/10.1037/ $\mathrm{a} 0014564$

Collins, P. H. (1999). Black feminist thought. Routledge.

Collins, P. H., \& Bilge, S. (2016). Intersectionality. Polity Press.

Crenshaw, K. (1991). Mapping the margins: Intersectionality, identity politics, and violence against women of color. Stanford Law Review, 43, 1241-1299.

Douglas, D., \& Attewell, P. (2017). School mathematics as gatekeeper. The Sociological Quarterly, 58(4), 648-669. https://doi. org/10.1080/00380253.2017.1354733

Duprey, M. A., Pratt, D. J., Jewell, D. M., Cominole, M. B., Fritch, L. B., Ritchie, E. A., Rogers, J. E., Wescott, J. D., \& Wilson, D. H. (2018). High school longitudinal study of 2009 (HSLS:09) base-year to second follow-up data file documentation (NCES 2018-140). National Center for Education Statistics, Institute of Education Sciences, U.S. Department of Education. 
Flores, A. (2007). Examining disparities in mathematics education: Achievement gap or opportunity gap? The High School Journal, 91(1), 29-42. www.jstor.org/stable/40367921

Gay, G. (2000). Culturally responsive teaching: Theory, research, and practice. Teacher's College Press.

Gonzalez, L. (2009). Teaching Mathematics for Social Justice: Reflections on a Community of Practice for Urban High School Mathematics Teachers. Journal of Urban Mathematics Education, 2(1), 22-51.

Gonzalez, L. (2016). Reimagining mathematics education in and for a democracy. Education in a democracy: A Journal of the National Network for Educational Renewal, 8, 93-109.

Grant, M. R., Compton, H., \& Ford, D. J. (2015). Black male students and the algebra project: Mathematics identity as participation. Journal of Urban Mathematics Education, 8(2), 87-118.

Gregory, A., Skiba, R. J., \& Noguera, P. A. (2010). The achievement gap and the discipline gap two sides of the same coin? Educational Researcher, 39(1), 59-68. https://doi.org/10.3102/0013189X09 357621

Gutiérrez, R. (2013a). The sociopolitical turn in mathematics education. Journal for Research in Mathematics Education, 44(1), 37-68. https://doi.org/10.5951/jresematheduc.44.1.0037

Gutiérrez, R. (2013b). Why (urban) mathematics teachers need political knowledge. Journal of Urban Mathematics Education, 6(2), 7-19.

Gutiérrez, R. (2017). Why mathematics education was late to the backlash party: The need for a revolution. Journal for Urban Mathematics Education, 10(2), 8-24.

Gutstein, E. (2012). Reading and writing the world with mathematics: Toward a pedagogy for social justice. Routledge.

Gutstein, E., \& Peterson, B. (2013). Rethinking mathematics: Teaching social justice by the numbers. Rethinking Schools.

High School Longitudinal Study of 2009. (2009). U.S. Dept. of Education, Institute of Education Sciences, National Center for Education Statistics.

Holland, D. C. (2001). Identity and agency in cultural worlds. Harvard University Press.

Jett, C. C. (2010). "Many are called, but few are chosen": The role of spirituality and religion in the educational outcomes of "chosen" African American male mathematics majors. The Journal of Negro Education, 79(3), 324-334.

Kincheloe, J. L., McLaren, P., \& Steinberg, S. R. (2018). Critical pedagogy and qualitative research: Advancing the bricolage. In N. K. Denzin \& Y. S. Lincoln (Eds.), The Sage handbook of qualitative research (pp. 235-260). Sage Publications.

Ladson-Billings, G. (2006). From the achievement gap to the education debt: Understanding achievement in US schools. Educational Researcher, 35(7), 3-12. https://doi.org/10.3102/0013189X03 5007003

Ledesma, M. C., \& Calderón, D. (2015). Critical race theory in education: A review of past literature and a look to the future. Qualitative Inquiry, 21(3), 206-222. https://doi.org/10.1177/1077800414 557825

Leonard, J., \& Martin, D. B. (Eds.). (2013). The brilliance of Black children in mathematics: Beyond the numbers and toward new discourse. Information Age.

LoGerfo, L., Christopher, E. M., \& Flanagan, K. D. (2011). High school longitudinal study of 2009 (HSLS:09). A first look at fall 2009 ninth-graders' parents, teachers, school counselors, and school administrators (NCES 2011-355). U.S. Department of Education,
National Center for Education Statistics. U.S. Government Printing Office.

Martens, P. J., Chateau, D. G., Burland, E. M. J., Finlayson, G. S., Smith, M. J., Taylor, C. R., Brownell, M. D., Nickel, N. C., Katz, A., \& Bolton, J. M. (2014). The effect of neighborhood socioeconomic status on education and health outcomes for children living in social housing. American Journal of Public Health, 104(11), 2103-2113. https://doi.org/10.2105/AJPH.2014.302133

Martin, D. B. (2000). Mathematics success and failure among AfricanAmerican youth: The roles of sociohistorical context, community forces, school influence, and individual agency. Routledge.

Martin, D. B. (2009). Does race matter? Teaching Children Mathematics, 16(3), 134-139.

Martin, D. B. (2012). Learning mathematics while Black. Educational Foundations, 26(1/2), 47-66.

Martin, D. B. (2013). Race, racial projects, and mathematics education. Journal for Research in Mathematics Education, 44(1), 316-333. https://doi.org/10.5951/jresematheduc.44.1.0316

Matthews, L. E., Jones, S. M., \& Parker, Y. A. (2013). Advancing a framework for culturally relevant, cognitively demanding mathematics tasks. In J. Leonard \& D. B. Martin (Eds.), The brilliance of Black children in mathematics: Beyond the numbers and toward new discourse (pp. 123-150). Information Age.

McGee, E. O. (2013a). Threatened and placed at risk: High achieving African American males in urban high schools. The Urban Review, 45(4), 448-471. https://doi.org/10.1007/s11256-013-0265-2

McGee, E. O. (2013b). Young, Black, mathematically gifted, and stereotyped. The High School Journal, 96(3), 253-263. https://doi. org/10.1353/hsj.2013.0011

Merton, R. K. (1948). The self-fulfilling prophecy. The Antioch Review, 8(2), 193-210. https://doi.org/10.2307/4609267

Moses, R. P., \& Cobb, C. E., Jr. (2001). Radical equations: Civil rights from Mississippi to the algebra project. Beacon Press.

Prieur, A., \& Savage, M. (2013). Emerging forms of cultural capital. European Societies, 15(2), 246-267. https://doi.org/10.1080/14616 696.2012.748930

Rothon, C., Goodwin, L., \& Stansfeld, S. (2012). Family social support, community "social capital" and adolescents' mental health and educational outcomes: A longitudinal study in England. Social Psychiatry and Psychiatric Epidemiology, 47(5), 697-709. https:// doi.org/10.1007/s00127-011-0391-7

Sadker, D., \& Sadker, E. S. (2012). Gender in the classroom. Routledge.

Solomon, Y. (2009). Mathematical literacy: Developing identities of inclusion. Routledge.

Solomon, Y., Lawson, D., \& Croft, T. (2011). Dealing with 'fragile identities': Resistance and refiguring in women mathematics students. Gender and Education, 23(5), 565-583. https://doi. org/10.1080/09540253.2010.512270

Steele, C. M. (2006). Stereotype threat and African-American student achievement. In D. Grusky \& S. Szwlwnyi (Eds.), The inequity reader (pp. 252-257). Westview Press.

Stein, M. K., Smith, M. S., Henningsen, M. A., \& Silver, E. A. (2000). Implementing standards-based mathematics instruction: A casebook for professional development. Teachers College Press.

Stigler, J. W., \& Hiebert, J. (1999). The teaching gap: Best ideas from the world's teachers for improving education in the classroom. Free Press.

Stinson, D. W. (2004). Mathematics as "gate-keeper" (?): Three theoretical perspectives that aim toward empowering all children with a key to the gate. The Mathematics Educator, 14(1), 8-18. 
Stinson, D. W. (2008). Negotiating sociocultural discourses: The counter-storytelling of academically (and mathematically) successful African American male students. American Educational Research Journal, 45(4), 975-1010. https://doi.org/10.3102/0002831208319723

Stinson, D. W. (2013). Negotiating the "White male math myth": African American male students and success in school mathematics. Journal for Research in Mathematics Education, 44(1), 69-99. https://doi.org/10.5951/jresematheduc.44.1.0069

Tramonte, L., \& Willms, J. D. (2010). Cultural capital and its effects on education outcomes. Economics of Education Review, 29(2), 200213. https://doi.org/10.1016/j.econedurev.2009.06.003
Villegas, A. M., \& Lucas, T. (2002). Educating culturally responsive teachers: A coherent approach. State University of New York Press.

How to cite this article: Gonzalez L, Chapman S, Battle J. Mathematics identity and achievement among Black students. School Science and Mathematics. 2020;120:456-466. https://doi.org/10.1111/ssm.12436 